
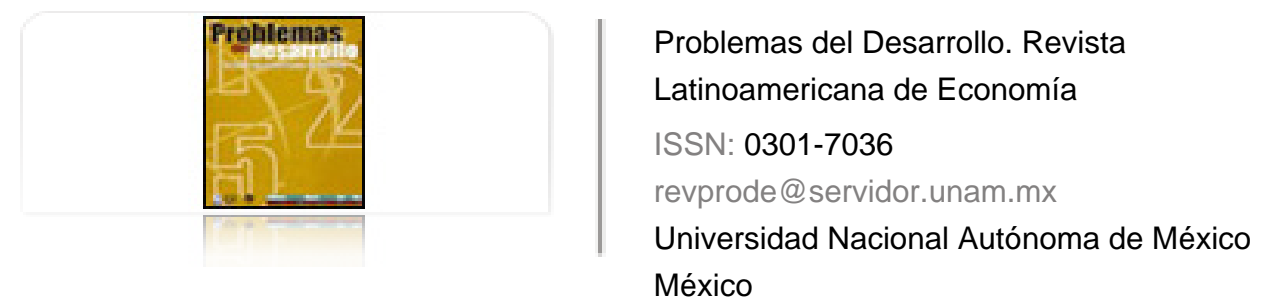

Reyes Guzmán, Gerardo; Moslares García, Carlos

LA UNIÓN EUROPEA EN CRISIS: 2008-2009

Problemas del Desarrollo. Revista Latinoamericana de Economía, vol. 41, núm. 161, abril-junio, 2010, pp. 13-39

Universidad Nacional Autónoma de México

Distrito Federal, México

Disponible en: http://www.redalyc.org/articulo.oa?id=11820105001

- Cómo citar el artículo

- Número completo

- Más información del artículo

- Página de la revista en redalyc.org

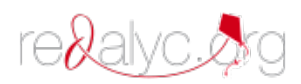

Sistema de Información Científica Red de Revistas Científicas de América Latina, el Caribe, España y Portugal Proyecto académico sin fines de lucro, desarrollado bajo la iniciativa de acceso abierto 


\title{
LA UNIÓN EUROPEA EN CRISIS: 2008-2009
}

\author{
Gerardo Reyes Guzmán* \\ Carlos Moslares García**
}

Fecha de recepción: 7 de febrero de 2010. Fecha de aceptación: 12 de abril de 2010.

\section{Resumen}

La crisis económica de 2008-2009 vulneró la solidez que la economía europea había presentado a lo largo de esa década. El desequilibrio económico de los países denominados PIIGS (Portugal, Italia, Irlanda, Grecia y España) provocó que las agencias calificadoras incrementaran el riesgo en sus deudas soberanas, lo que a su vez repercutió en un debilitamiento de la moneda europea. El inicio de la debacle fiscal griega en 2010 constituye una de las secuelas más serias de la crisis; superarla será un reto adicional para el Banco Central Europeo y los miembros de la Unión Europea en relación con el futuro de la moneda común.

Palabras clave: Unión Europea, crisis económica, zona euro, desequilibrio macroeconómico, riesgo país.

* Profesor-investigador de Economía Internacional, Universidad Iberoamericana, Puebla. Correo electrónico: gerardoreyesguzman@gmail.com. Agradezco el apoyo para la elaboración de este artículo al Campo Estratégico en Pobreza y Exclusión Puebla, al DAAD y al área de Estudios del Desarrollo de la Universidad de Göttingen, Alemania, en particular al Prof. Dr. Stephan Klasen.

** Profesor-investigador de Economía Internacional, Universidad Ramón Llull, Barcelona. Correo electrónico: moslares@iqs.url.es 


\section{Abstract}

The economic crisis of 2008-2009 undermined the solidity that the European economy had exhibited during that decade. The economic disequilibrium of the countries known as the PIIGS (Portugal, Italy, Ireland, Greece and Spain) led rating agencies to increase their sovereign risk rates, and this caused a weakening of the euro. The beginning of Greece's fiscal collapse in 2010 constitutes one of the most serious sequels in the crisis -overcoming it will be yet another challenge for the European Central Bank and the members of the European Union, related to the future of the common currency.

Keywords: European Union, economic crisis, euro zone, macroeconomic disequilibrium, country risk.

\section{Résumé}

La crise économique de 2008-2009 a vulnérabilisé l'économie européenne qui s'était pourtant montrée solide tout au long de cette décennie. Le déséquilibre économique des pays dénominés PIIGS (Portugal, Italie, Irlande, Grèce et Espagne) a provoqué l'augmentation par les agences qualificatrices du risque associé à leurs dettes souveraines, ce qui a entraîné un affaiblissement de la monnaie européenne. Le début de la débacle fiscale grecque en 2010 constitue une des séquelles les plus graves de la crise; la surpasser sera un défi de plus pour la Banque Centrale Européenne et les membres de l'Union Européenne liés au futur de la monnaie commune.

Mots clés: Union Européenne, crise économique, zone euro, déséquilibre macroéconomique, risque pays.

\section{Resumo}

A crise econômica de 2008-2009 vulnerou a solidez que a economia europeia havia apresentado ao longo dessa década. O desequilíbrio econômico dos países denominados PIIGS (Portugal, Itália, Irlanda, Grécia e Espanha) provocou que as agências qualificadoras incrementassem o risco em suas dívidas soberanas, o que por sua vez repercutiu num debilitamento da moeda europeia. O início da débâcle fiscal grega em 2010 constitui uma das sequelas mais sérias da crise; superá-la será um desafio adicional para o Banco Central Europeu e os membros da União Europeia com relação ao futuro da moeda comum.

Palavras-chave: União Europeia, crise econômica, zona euro, desequilíbrio macroeconômico, risco país. 


\section{Introducción}

e enero de 2002 a junio de 2008 el tipo de cambio dólar-euro pasó de 0.859 a

1.55 , reflejando así un inusitado fortalecimiento de la Unión Europea respecto de la economía norteamericana. No obstante, la crisis financiera de 2008 hizo que el dólar se apreciara súbitamente, pues muchos inversionistas, arrastrados por el pánico, se deshicieron de sus activos nominados en euro para refugiarse en los tradicionales Bonos del Tesoro norteamericano. Para mediados de febrero de 2009, la cotización llegó hasta 1.3 dólares por euro. Este fenómeno creo confusión en los mercados financieros pues la confianza depositada en la Unión Monetaria Europea se vio vulnerada repentinamente por la crisis. Por otro lado, en las reuniones cumbre de los G20 (Washington: noviembre de 2008; Londres: abril de 2009, y Pittsburg: septiembre de 2009), se reconoció que la práctica de una política monetaria laxa en combinación con un exceso de liquidez habían alimentado una generalizada burbuja bursátil en el hemisferio occidental, que desembocó en una debacle financiera mundial. Ahí se enfatizó no sólo que la crisis se había originado en los Estados Unidos de América, sino que había afectado seriamente al sistema financiero europeo.

Con base en lo anterior y enfocándonos en el caso de la Unión Europea, nos planteamos las siguientes preguntas: ¿Cuáles son las debilidades económicas de la Zona Euro que animaron a los inversionistas a dudar de su capacidad para enfrentar la crisis? ¿Mediante qué mecanismos y cómo se transmitió la crisis de los Estados Unidos a la Unión Europea? ¿Cómo se vio afectada la Zona Euro y qué retos planteó la crisis a la moneda europea? ¿En qué medida y qué países resultaron más dañados? ¿Qué repercusiones tiene el rescate de la deuda griega para la estabilidad del euro? Durante la crisis, ¿cómo se desempeñaron los países de la Unión Europea que no forman parte del euro y qué repercusiones hubo respecto a sus aspiraciones para formar parte del euro en el mediano plazo?

Para dar respuesta a estas preguntas se han preparado cuatro apartados. En el primero se rescatan las premisas básicas de quienes concibieron una Unión Monetaria, principalmente en lo que concierne a cómo este modelo debía enfrentar una crisis económica. En el segundo, se analiza el mecanismo por medio del cual la crisis de los Estados Unidos se transmitió a la Zona Euro y cómo se manifestó ésta a nivel macroeconómico entre los países miembro durante 2009. Para ello se seleccionaron algunos indicadores macroeconómicos de primer nivel, que se ordenan de mayor a menor con base en su solidez, y se analiza caso por caso. En la tercera parte se utiliza la misma metodología pero para los países de la Unión Europea que no forman parte del euro. El cuarto apartado se ocupa de la más reciente controversia desatada por 
Grecia, a raíz de las dificultades de su gobierno para hacer frente a sus compromisos de deuda. Finalmente, en las conclusiones se retoman los puntos más relevantes para reflexionar en torno al significado de la crisis y los retos que representa para el futuro de la Unión Europea.

\section{Restricciones teóricas de la Unión Monetaria}

De Grawe ${ }^{1}$ (1997) explica el funcionamiento de una Unión Monetaria a partir de un modelo de dos países: Francia y Alemania. Supone, por ejemplo, que se presenta un choque de la demanda en Francia, de tal manera que los franceses se inclinan fuertemente por el consumo de productos alemanes (fig. 1). El resultado es que la demanda se contrae en Francia y se expande en Alemania. En otras palabras, se registrará una recesión en Francia y una expansión en Alemania; un aumento del desempleo en el primero y una insuficiente mano de obra para responder a una mayor demanda en el segundo; una balanza comercial deficitaria en Francia y superavitaria en Alemania. Si en Francia los trabajadores despedidos reciben un seguro de desempleo, surgirá un déficit público en ese país y, al contrario, un superávit en Alemania. El desequilibrio aquí planteado requerirá un ajuste.

\section{Figura 1}
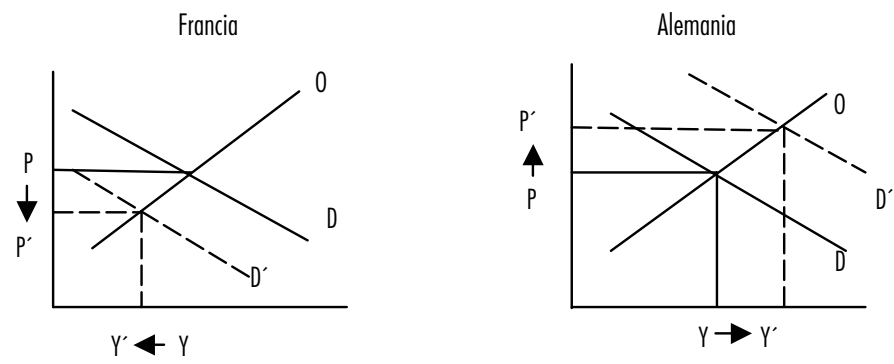

En el marco de una Unión Monetaria, el equilibrio se puede restablecer mediante la puesta en marcha de las siguientes políticas:

a) Flexibilidad de salarios. En Francia, los trabajadores reducirán sus demandas salariales y en Alemania las aumentarán. La reducción de los salarios en Francia

1 Paul De Grawe es un economista belga, conocido no sólo por sus aportaciones a los escritos de Unión Monetaria, sino por su corte neokeynesiano. Propone una intervención del Estado en momentos de crisis y una recuperación del déficit público en épocas de auge. Además, es un fuerte crítico de las expectativas racionales en análisis macroeconómicos y un candidato a ocupar la dirección del Banco Central Europeo (Wirtschaftswoche, 16/11/2009: 47). 
provocará un desplazamiento de la curva de la oferta hacia la derecha. En Alemania la oferta se corre hacia la izquierda. A través de ello se genera un proceso de competitividad que favorece a Francia y se restablece el equilibrio.

b) Movilidad de la mano de obra. Como resultado del desequilibrio arriba mencionado, la mano de obra escasea en Alemania y se vuelve excesiva en Francia. Por lo tanto, habrá una emigración de trabajadores franceses hacia Alemania. Ello hará reducir el desempleo en Francia, mientras que en Alemania los salarios se congelarán o incluso tenderán a la baja. Análogamente, el déficit fiscal en Francia disminuirá al no tener que transferir recursos a los desempleados, mientras que en Alemania el nivel de precios no se verá presionado por demandas salariales.

c) Flexibilidad de precios. En caso de que los salarios y la movilidad de la mano de obra sean rígidos, persistirá el desequilibrio. Entonces, un proceso inflacionario en Alemania y una caída de los precios en Francia garantizaría el equilibrio por el efecto de competitividad.

d) Política fiscal. Otra alternativa sería la aplicación de una política fiscal restrictiva en Alemania. Con ello, los recursos superavitarios recaudados en ese país se transferirían a Francia para que ahí se pudiera aplicar una política de gasto. Aun cuando este proceso de redistribución de los recursos fiscales se practique abiertamente en Alemania, es muy probable que dentro de una Unión Monetaria fuera difícil llegar a semejante consenso. A largo plazo, lo ideal sería que la flexibilidad de salarios y precios, junto con la movilidad de la mano de obra, garantizaran el restablecimiento del equilibrio.

De lo anterior se deriva que países con rigideces severas en salarios y precios, así como en la movilidad de los factores de la producción, enfrentarán costos más altos al decidir formar una Unión Monetaria. Luego entonces, el conservar sus respectivas monedas y aplicar una política devaluatoria podría ser más favorable para superar el desequilibrio. Se puede concluir que las condiciones óptimas para sostener una Unión Monetaria son: $a$ ) flexibilidad de precios y salarios y $b$ ) movilidad de la mano de obra. Una Unión Monetaria entre países con distintos niveles de inflación, sistemas fiscales, desarrollo estructural y organizaciones laborales requerirá un consenso político de cierta complejidad para poder materializarse. En especial en países subdesarrollados con problemas de escasez de recursos públicos, los gobiernos están continuamente tentados a hacer uso del impuesto inflacionario para aumentar sus ingresos. Con la Unión Monetaria, la política fiscal deberá practicarse considerando el equilibrio de la región en general y a favor de la estabilidad monetaria. 
Mundell (1961: 662), por su parte, establece que para evitar crisis cambiarias, el mundo debería dividirse en áreas monetarias óptimas bajo criterios de movilidad factorial. Reconoce que el mayor obstáculo es de orden político, debido al símbolo de identidad y soberanía de las diferentes monedas nacionales. Advierte que decidirse por una moneda común implica comparar los altos costos relacionados con la existencia de monedas nacionales y los beneficios que las áreas monetarias óptimas traen consigo, pues entre más monedas nacionales existan, mayores serán los costos de conversión y menor la eficiencia con la que el dinero cumple sus funciones. Cabe señalar que Mundell favorece el régimen de tipo de cambio flexible sólo entre las regiones cuya movilidad factorial es pobre. McKinnon (1963: 717-719) enriquece la discusión puntualizando que en el área monetaria óptima existen tres objetivos, que se pretenden alcanzar a través de las políticas monetaria, fiscal y cambiaria: a) pleno empleo, $b$ ) equilibrio externo y $c$ ) estabilidad de precios. Uno de los factores decisivos para el buen funcionamiento del área monetaria óptima es el nivel de comercio entre los países y la relación entre bienes comerciables y no comerciables. Si los bienes comerciables superan en importancia a los no comerciables, el tipo de cambio fijo será preferible al tipo de cambio flexible, ya que una devaluación de la moneda para corregir un déficit en cuenta corriente repercutiría en un aumento de los precios que a su vez tendría que ser contrarrestado con políticas restrictivas de orden fiscal y monetario. Ello significaría incurrir en un proceso recesivo de altos costos sociales. Por el contrario, bajo un tipo de cambio fijo o área monetaria óptima, el gobierno se verá obligado a reducir su gasto para corregir el desequilibrio externo, liberando bienes que antes se consumían en el mercado interno para ahora exportarlos y reducir así el déficit comercial. Agrega que entre mayor sea el flujo de comercio y la movilidad factorial entre dos regiones, menos eficiente será el tipo de cambio flexible y más adecuada será una moneda única para alcanzar el objetivo de pleno empleo y equilibrio externo. El área monetaria óptima hará que los flujos de capital entre los integrantes de la región sean más estables, y concluye su clásico artículo afirmando que no solamente la movilidad factorial entre las fronteras es importante, sino también entre las industrias. Es decir, la movilidad entre las industrias podría reemplazar a la movilidad factorial en la medida en que fuera posible contrarrestar un choque externo mediante el establecimiento de industrias en las regiones que enfrentan déficit externo y desempleo.

En la práctica, los supuestos teóricos mencionados por De Grawe y planteados por Mundell y Mackinnon estuvieron lejos de materializarse a cabalidad en la Unión Monetaria, excepto el comercio, pues la mayor parte de éste se lleva a cabo entre los 
países miembro. Sin embargo, la flexibilidad de precios y salarios, así como el aspecto fiscal permanecieron débiles. No obstante, la sostenibilidad de la Unión Monetaria Europea tuvo que descansar en requerimientos mínimos, plasmados en los criterios de convergencia del Tratado de Maastricht (Fritzler y Unser, 1998: 87), a saber:

1) La tasa de inflación no puede ser mayor que un $1.5 \%$ respecto a la media de los tres estados de la Eurozona con menor inflación.

2) El déficit gubernamental no debe ser mayor a $3 \%$ del PIB.

3) La deuda total no puede rebasar el $60 \%$ del PIB.

4) La tasa de interés a largo plazo no debe exceder más de dos puntos arriba del interés que registran tres de las naciones con mayor estabilidad en sus precios.

5) Haber formado parte del Sistema Monetario Europeo por lo menos durante dos años.

A continuación, llevaremos a cabo un análisis orientado en los criterios de convergencia, que se enfoca en los siguientes agregados macroeconómicos: a) crecimiento económico, $b$ ) déficit en cuenta corriente respecto al PIB, $c$ ) deuda pública en relación con el PIB y $d$ ) tasa de desempleo. Con ello no sólo se pretende indentificar qué países rebasan las restricciones de los criterios de Maastricht, sino lo que ello implica en sus decisiones de política económica para superar la crisis.

\section{La Zona Euro en crisis: mercados financieros y economía real}

La gráfica 1 advierte la caída de las principales bolsas europeas como el primer impacto que tuvo la crisis de los Estados Unidos en la Unión. El índice español IGME descendió 53\% al pasar de 1720 puntos en octubre de 2007 a 803.92 en febrero de 2009. El Dax 30 de Alemania cayó 40\% al pasar de 7861 puntos a 4 769.45; el FTSE de Londres, 38\% de octubre de 2007 (6 721.60) a enero de 2009 (4 149 puntos) y el CAC de Francia -50\% al pasar de 6054.93 puntos en junio de 2007 a sólo 2973.92 en enero de 2009. No obstante, todos repuntaron tras tocar fondo el 31 de diciembre de 2008. Ya para el 9 de noviembre de 2009 se habían recuperado: FSTE 100 en 31.3\%; DAX 30: 40.4\%; IGME: 40.6\% y CAC 40: 42.7\%. La correlación de estos índices con el Dow Jones es muy relevante. El índice FSTE 100 de Londres acusa la más alta correlación con un coeficiente de 0.9225; le sigue el CAC 40 de Francia con 0.9235; el IGME de España 0.8807 y el DAX de Alemania con 0.8691. Un acontecimiento decisivo en la caída de las bolsas europeas fue la quiebra de Lehman Brothers el 15 de septiembre de 2008. Considerado el cuarto banco de inversión del mundo, contaba 
con un total de 55000 cuentas y US $\$ 150000$ millones en deudas de corto plazo a favor de diversas empresas, aseguradoras, bancos, gobiernos, fondos de inversión, etc. (Focus, 2009: 128). En el caso de Alemania, el banco más afectado fue el Hypo Real Estate (HRE), pero también Lufthansa y el Deutsche Bank, entre otros. El gobierno alemán tuvo que respaldar con 100000 millones de euros (mme) al HRE. A partir de ello, se lanza en Europa el European Economic Recovery Plan en noviembre de 2008, con un paquete de rescate de 200 mme, equivalentes a 1.5\% del PIB de la Unión Europea (European Commission, 19/01/2009: 1). A su vez, dicho documento señala que el principal detonante de la recesión en la Unión Europea fue el congelamiento del crédito a la economía real. Ello obligó a las empresas a disponer de su propio capital para superar problemas de liquidez de corto plazo, pero conforme éste se consumió, entraron en un rango de alto riesgo frente a los bancos, lo que les dificultaba aún más el acceso al crédito, o bien, debían aceptar una tasa de interés mayor. Lo mismo sucedió con aquellas que echaron mano de sus inventarios durante la crisis y que una vez normalizados los pedidos se vieron en la necesidad de recurrir al crédito para financiar la compra de material ligada al restablecimiento de la producción, crédito que pocas veces se autorizó (Körner, et al., 2009). En este contexto, los acuerdos de los $\mathrm{G} 20^{2}$ para enfrentar la crisis terminaron por entorpecer actividades bancarias tradicionales, lo que desalentó aún más la recuperación económica ${ }^{3}$.

Como se aprecia en la gráfica 2, existe una correlación entre el crecimiento económico de la Unión Europea y los Estados Unidos. La correlación de Pearson para el periodo del trimestre 2000-I al 2009-II es de 0.5504 con una $\mathrm{R}^{2}$ de 0.3029; de donde se deriva que por cada punto porcentual de los Estados Unidos, el PIB de Europa varía en 0.39 puntos. Si bien la correlación es significante, la recesión norteamericana

2 Como resultado de las reuniones de los G-20 celebradas en Washington, Londres y Pittsburg entre noviembre de 2008 y septiembre de 2009, se determinó crear un mecanismo regulador de validez internacional, listo para operar a más tardar a finales de 2010. Se trata de que los bancos aporten una mayor participación de capital propio. Análogamente, se pondría en marcha un nuevo nivel de endeudamiento no basado en el riesgo y en adición a lo estipulado por los acuerdos de Basilea II.

3 Ejemplo de ello es la quiebra de Quelle, a finales de octubre de 2009. Esta empresa alemana de artículos para el hogar, con 50 años de antigüedad, dejó desempleados a cerca de 10000 trabajadores. Hasta antes de la crisis, los bancos adquirían las deudas de los clientes para negociar con ellos una forma de pago atractiva (operación de factoraje), y proveían a la empresa con liquidez para que ésta pudiera operar. Una de las condiciones que el gobierno alemán impuso a los bancos rescatados, fue abstenerse de incurrir en operaciones de riesgo. Este tipo de factoraje cayó en ese renglón y fue prohibido. Con ello, los pedidos se detuvieron, las mercancías se quedaron en el almacén y la actividad entera se congeló, orillando a la empresa a la bancarrota (Hoffritz, 22/10/2009: 25). 
Gráfica 1

Principales bolsas de valores europeas vs. Dow Jones 2002-2009

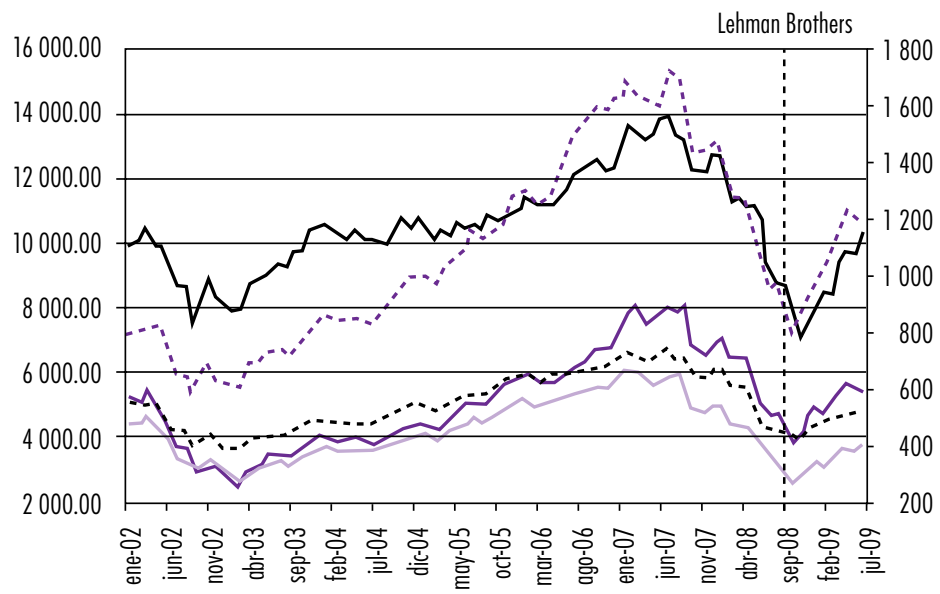

IGME

Tabla 1

Dow Jones

\begin{tabular}{|l|c|c|c|}
\hline & Coeficiente de correlación & $R^{2}$ & Regresión \\
\hline IGME & 0.8807 & 0.7758 & IGME $=0.1784$ (DJ) -790.92 \\
\hline DAX 30 & 0.8691 & 0.7554 & DAX 30 $=0.7875$ (DJ) -3182.9 \\
\hline FTSE & 0.9225 & 0.9179 & FTSE $=0,4904$ (DJ) -71.145 \\
\hline CAC 40 & 0.9235 & 0.8530 & CAC 40 $=0,541$ (DJ) -1494.8 \\
\hline
\end{tabular}

Fuente: Elaboración propia con funciones estadísticas de Excel y datos de Yahoo Finanzas. Disponible en: $\mathrm{http}: / /$ es.finance. $y$ ahoo.com/q/hp?s=\%5EDJI\&b=1\&a=06\&c=2009\&e=20\&d=10\&f=2009 $\& \mathrm{~g}=\mathrm{m}$

Las $\mathrm{R}^{2}$ señalan el grado de significancia de la correlación, y las ecuaciones de regresión la variación de cada índice a partir de una unidad marginal del Dow Jones.

afectó de manera distinta a los países de la Zona Euro. Como señala la gráfica 3, el país con la mayor caída del PIB en 2009 fue Alemania, con más del 5\%; le siguió Irlanda y posteriormente en una intensidad similar España, Italia, Bélgica, Francia y Portugal; Finlandia, Austria y Luxemburgo tuvieron una modesta caída, y Grecia, Malta, Chipre, Holanda, Eslovenia y Eslovaquia no sufrieron retroceso alguno. En lo referente al déficit en cuenta corriente con relación al PIB (gráfica 4), tenemos que los países con mayor desequilibrio externo son Chipre, Grecia, Portugal y España. Estos déficit de cuenta corriente fueron financiados por una importante entrada de capital extranjero (importadores de capital), que sostuvo a su vez el incremento de su respectiva demanda interna. Por otro lado, los superavitarios son Holanda, Luxemburgo, 
Gráfica 2

PIB Unión Europea vs. Estados Unidos

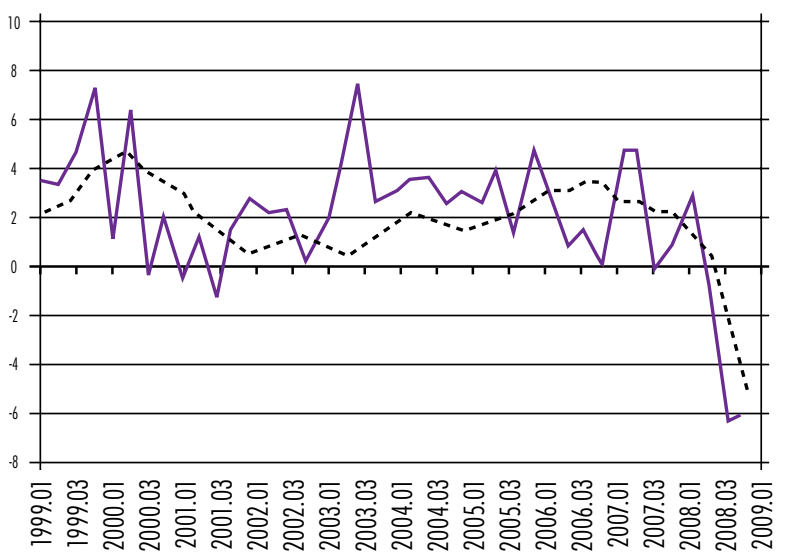

-...- PIB UE — PIB EEUU

Gráfica 3

Crecimiento económico 2009 en la Zona Euro

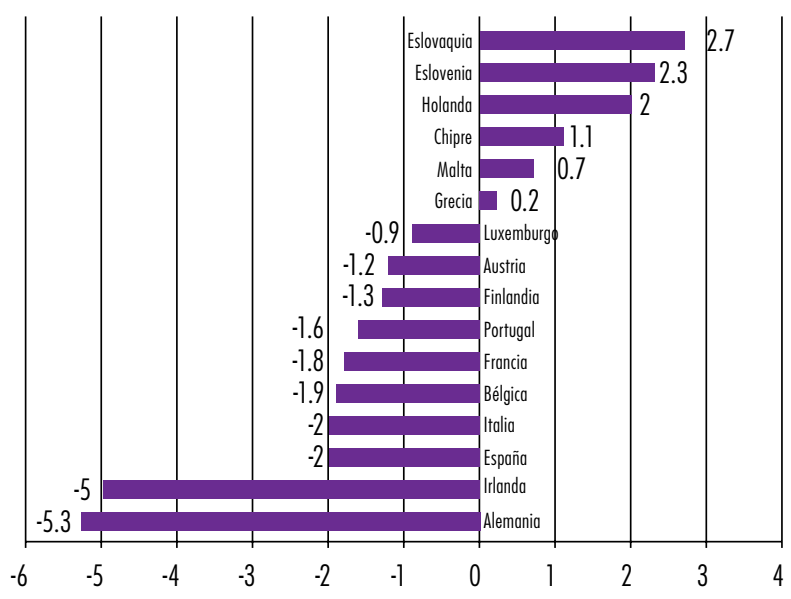

Fuente: Estadísticas históricas, disponible en: http://www.cefp.gob.mx/intr/estadisticas/copianewe_stadisticas. html\#14. European Central Bank-Statistical Data Warehouse-Quick Viewm, disponible en: http://sdw.ecb.europa.eu/quickview.do?SERIES_KEY=122.ICP.M.U2.N.000000.4.ANR y European Commission (19 de enero de 2009). Interim Forcast. Directorate-General for Economic and Financial Affairs. Disponible en: http://ec.europa.eu/economy_finance/pdf/2009/interimforecastjanuary/interim_forecast_jan_2009_en.pdf 
Alemania, Finlandia y Austria, lo que al mismo tiempo los convierte en exportadores de capital. En lo referente al endeudamiento público respecto al PIB (gráfica 5), los países que rebasan los criterios de convergencia de Maastricht son: Italia, Grecia y Bélgica; seguidos en menor escala por Francia, Alemania, Portugal, Malta y Austria. Por el tamaño de sus economías, el endeudamiento público de Francia, Alemania y Austria cobra singular importancia.

Gráfica 4

Saldo de la cuenta corriente con respecto al PIB en la Zona Euro (2008)

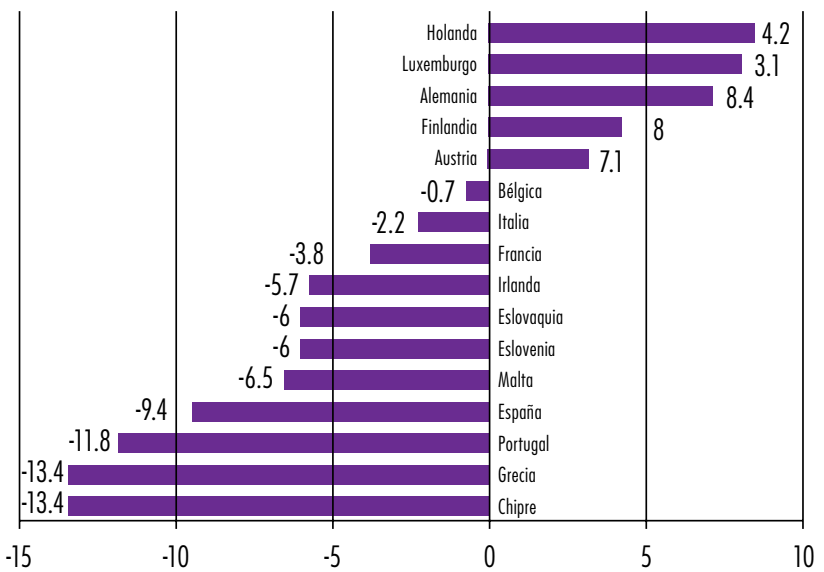

Gráfica 5

Deuda pública con respecto al PIB 2009 en la Zona Euro (\%)

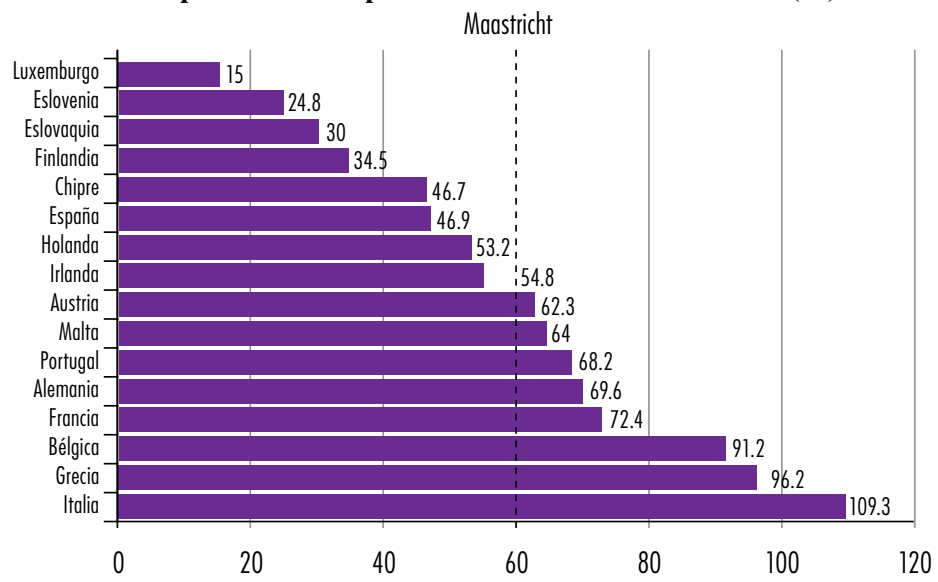

Fuente: European Commission (19 de enero de 2009). Interim Forcast. Directorate- General for Economic and Financial Affairs. Disponible en: http://ec.europa.eu/economy_finance/pdf/2009/interimforecastjanuary/ interim_forecast_jan_2009_en.pdf 
Las gráficas 6 y 7 nos muestran los índices de inflación anual y la tasa de desempleo estimada para 2009. Los países cuyo índice de precios rebasa los criterios de Maastricht son Eslovenia, Malta, Bélgica, Chipre y Grecia. Los que presentan más altas tasas de desempleo son España, Eslovaquia, Francia, Irlanda, Grecia y Portugal, mientras que Holanda aparece como el país menos afectado. El caso de Francia se ha distinguido por su renuencia a corregir su desequilibrio fiscal, tal y como lo sugiere la Comisión Europea. El déficit del gobierno francés para 2010 se estima en 8.2\% del PIB, y el gobierno de Sarkozy ha solicitado un nuevo préstamo de 35 mme para el financiamiento de proyectos de infraestructura, educación y desarrollo tecnológico. Ello ha provocado temores de un ajuste en la calificación de deuda soberana, tal y como ocurre con Grecia y España. Asimismo, la semana de 35 horas ha contribuido al descenso de la productividad y competitividad en ese país, fenómeno que se observa en un creciente déficit comercial. Por su parte, la rigidez en el mercado laboral ha redundado en un aumento del desempleo, alcanzando hasta $20 \%$ entre los jóvenes (Wirtschafstwoche, 30/11/2009: 30-33).

En este tenor, llama la atención que Alemania figure como el país con mayor descenso del PIB durante 2009, pero su tasa de desempleo no esté entre las más altas. Dettmer (et al., 2009) señala que las empresas alemanas se prepararon para enfrentar la crisis y que el programa de reducción de las horas de trabajo (Kurzarbeit) fue decisivo para evitar un despido masivo de trabajadores. De acuerdo con el autor, 1.1 millones de trabajadores alemanes se acogieron a dicho programa. Por el contrario, el colapso del sector inmobiliario en España lanzó a miles de trabajadores a la calle, lo que junto con su rigidez laboral (salarios altos y dificultad para despedir empleados en el sector formal) agudizó el problema. El nivel de desempleo afectó principalmente a los jóvenes. En un artículo publicado por el semanario alemán Wirtschaftswoche (10/08/2009: 23), se estima un desempleo promedio entre jóvenes menores de 25 años que alcanza 19.6\% en los 27 países que integran la Unión Europea. La lista está encabezada por España con 36.5\%, seguida por Italia, 24.9\%; Grecia, 24.4\%; Francia, 23.8\%; Bélgica, 22.3\%, y Portugal con 19.8\%, entre los más importantes.

La tabla 2 ordena los países con base en el lugar que ocupan tomando en cuenta cada uno de los cinco agregados macroeconómicos seleccionados. El propósito es diferenciar los 16 países de la Zona Euro de acuerdo con su solidez macroeconómica. Así, por ejemplo, Bélgica es el quinto país con menor crecimiento económico; el undécimo con mayor déficit de cuenta corriente respecto al PIB; el octavo con mayor tasa de desempleo; el tercero con mayor deuda en relación con su PIB, y el tercero con mayor inflación. La suma aritmética de los puntos según el lugar ocupado se 
observa en la gráfica 8. Los países con menor puntuación son aquellos que muestran peor estabilidad macroeconómica y, por tanto, fueron los más afectados por la crisis económica. Este grupo está formado por Grecia, España, Bélgica e Italia. En 2008, la calificadora Standard \& Poors había designado a estos países las calificaciones de A, AAA, AA+ y A+, respectivamente; mientras que Portugal e Irlanda ostentaban calificaciones de AA- y AAA, respectivamente. En contraste, los países más sólidos fueron Holanda, Luxemburgo, Austria y Finlandia.

Gráfica 6

Tasa de inflación anualizada 2008 en la Zona Euro

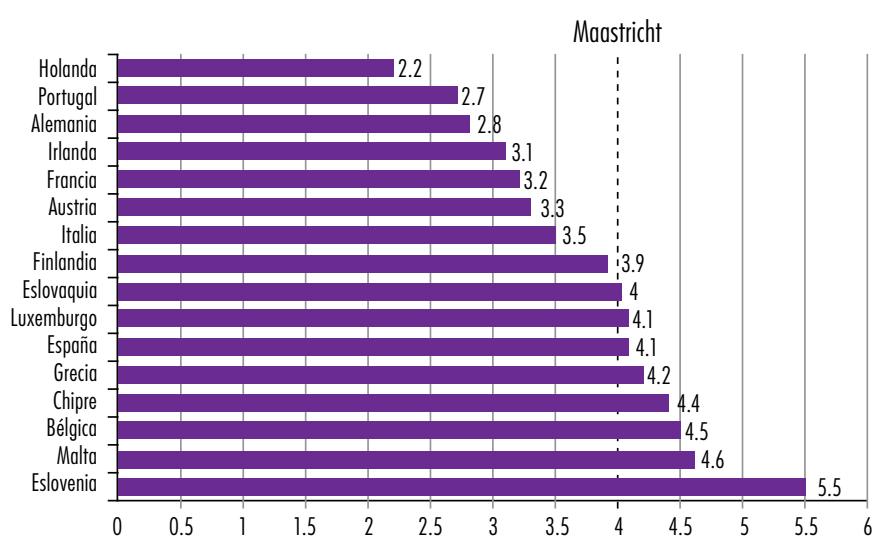

Gráfica 7

Tasa anual de desempleo en la Zona Euro 2009 (\%)

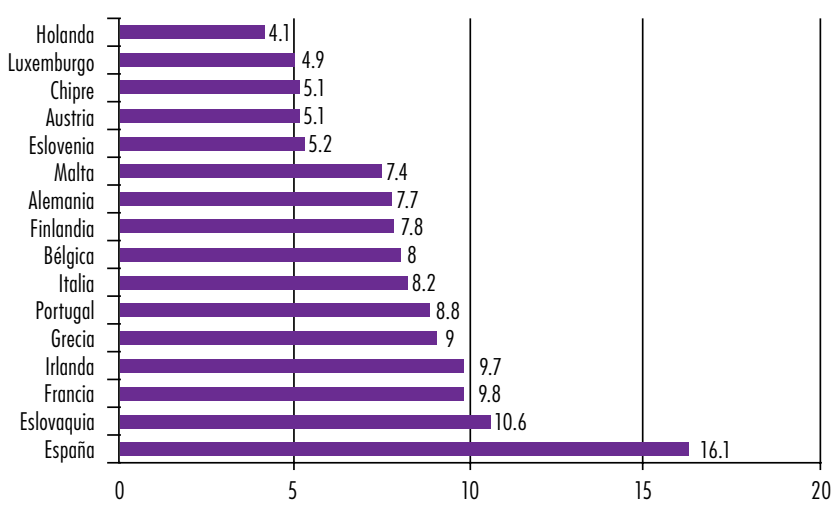

Fuente: European Commission (19 de enero de 2009). Interim Forcast. Directorate- General for Economi and Financial Affairs. Disponible en: http://ec.europa.eu/economy_finance/pdf/2009/interimforecastjanuary interim_forecast_jan_2009_en.pdf 
Tabla 2

\begin{tabular}{|c|l|r|r|r|r|c|}
\hline Clave & País & $\begin{array}{c}\text { Menor crecimiento } \\
\text { económico 2009 }\end{array}$ & $\begin{array}{c}\text { Mayor déficit } \\
\text { cuenta corriente/PIB }\end{array}$ & $\begin{array}{c}\text { Tasa más alta } \\
\text { de desempleo 2009 }\end{array}$ & $\begin{array}{c}\text { Mayor deuda/ } \\
\text { PIB 2009 }\end{array}$ & $\begin{array}{c}\text { Más alta tasa } \\
\text { de inflación 2008 }\end{array}$ \\
\hline \multicolumn{7}{|c|}{16 países miembro de la Zona Euro } \\
\hline BE & Bélgica & 5 & 11 & 8 & 3 & 3 \\
\hline DE & Alemania & 1 & 14 & 10 & 5 & 14 \\
\hline IE & Irlanda & 2 & 8 & 4 & 9 & 13 \\
\hline EL & Grecia & 11 & 2 & 5 & 2 & 5 \\
\hline ES & España & 3 & 4 & 1 & 11 & 6 \\
\hline FR & Francia & 6 & 9 & 3 & 4 & 12 \\
\hline IT & Italia & 4 & 10 & 7 & 1 & 10 \\
\hline CY & Chipre & 13 & 1 & 14 & 12 & 4 \\
\hline LU & Luxemburga & 10 & 15 & 15 & 16 & 7 \\
\hline MT & Malta & 12 & 5 & 11 & 7 & 2 \\
\hline NL & Holanda & 14 & 16 & 16 & 10 & 16 \\
\hline AT & Austria & 9 & 12 & 13 & 8 & 11 \\
\hline PT & Portugal & 7 & 3 & 6 & 6 & 15 \\
\hline SI & Eslovenia & 15 & 6 & 12 & 15 & 1 \\
\hline SK & Eslovaquia & 16 & 7 & 2 & 14 & 8 \\
\hline FI & Finlandia & 8 & 13 & 9 & 13 & 9 \\
\hline
\end{tabular}

Fuente: Elaboración propia con datos de European Commission (19 de enero de 2009). Interim Forcast. Directorate- General for Economic and Financial Affairs. Disponible en: http://ec.europa.eu/economy_ finance/pdf/2009/interimforecastjanuary/interim_forecast_jan_2009_en.pdf

De 2000 a 2005 la tasa de referencia del Banco Central Europeo fue descendente. Sin embargo, una tasa de interés única para la Zona Euro tuvo repercusiones distintas entre los países miembro. Para aquellos con altas presiones inflacionarias como Grecia, Irlanda y España, la tasa de interés resultaba muy baja y en su momento estimuló el auge en el sector de la construcción; mientras que para Alemania, con su tradicional estabilidad de precios, la misma tasa se percibía como demasiado alta. En el caso de España, el auge en la construcción estuvo auspiciado por las autoridades (ayuntamientos), no sólo al proporcionar terrenos y aprobar proyectos de construcción, sino facilitando el crédito a través de las cajas de ahorro, de lo que también se beneficiaban funcionarios públicos. A finales de 2008 se calculaba 1 millón de casas sin vender (The Economist, 11/11/2008).

Dirk Meyer (2009) enfatiza que la Unión Monetaria impide a los países que enfrentan severos déficit de cuenta corriente y una aguda recesión, recurrir a la depreciación de la moneda para corregir sus desequilibrios. Ello se cuestiona aún más con el aumento del desempleo, pues los gobiernos se ven obligados a replantear los beneficios que les significa ser miembros de la Zona Euro. En este tenor, la rigidez de los acuerdos de convergencia de Maastricht, así como la cláusula de prohibición de 
rescate financiero a un país miembro ${ }^{4}$, tuvieron que ser revisados. No sólo eso, junto con los cuantiosos paquetes gubernamentales de rescate financiero, calculados en 1.7 billones de euros, el Banco Central Europeo relajó la política monetaria en pro de la superación de la crisis, no obstante los riesgos inflacionarios que de ello se pudieran derivar. Sin embargo, no hay garantía de que dichas medidas hayan sido suficientes para superar la crisis, por lo que Meyer (2009) reflexiona en torno a posibles escenarios que pongan en entredicho la Zona Euro. El rompimiento puede venir de una falta de solvencia y competitividad de países con altos déficit fiscales y de cuenta corriente (déficit gemelos), así como de la imposibilidad de ser asistidos por los países miembro más estables de la Zona Euro. Y es que los 200 mme programados por la Unión Europea para financiar el programa de coyuntura hasta 2013, se agotaron en 2009; y al no haber una voluntad política para seguir apoyando a los países más débiles, su salida de la Zona Euro sería inminente. Meyer (2009) plantea en su hipótesis que los canditatos a abandonar el euro serían Irlanda, Grecia, España, Italia y Austria. En estos países se presentan tres factores que podrían deteriorar aún más sus déficit gemelos: a) las dificultades de pago de los países bálticos, Ucrania y Belorrusia, que fungen como sus principales socios comerciales; $b$ ) el deterioro de sus respectivos sectores inmobiliario e hipotecario, y $c$ ) la rigidez en sus mercados laborales. Un posible escenario es su salida de la Zona Euro para retornar a sus respectivas monedas, no sin antes vulnerar la estabilidad del resto de los países miembro, y sin ninguna garantía de que al hacerlo pudieran mejorar su situación. Este escenario ya se percibe en los mercados de capitales a través de la exigencia de una mayor tasa de interés en la compra de bonos de deuda emitidos por los gobiernos en cuestión. A principios de diciembre de 2009, los tres déficit fiscales más grandes de países miembro de la Unión (Grecia: -12.7\%; Irlanda: -12.5\%, y España: -11.25\%) motivaron a las agencias calificadoras a modificar sus notas. Después de que Fitch le hubiera asignado a Grecia la nota BBB+, destacándose como la más baja de la Unión Europea, S\&P castigó a España ${ }^{5}$ con la nota AA+ de menor grado (The Wall Street Journal, 10/12/2009: 4).

4 Existen dos cláusulas en el Tratado de la Unión: a) El Banco Central Europeo tiene prohibido financiar déficit fiscales, y la no-bail-out-klausel del artículo 103 prohibe el rescate financiero de un miembro en dificultades fiscales por parte del resto (Meyer, 2009: 52; The Economist, 13/06/2009: 13).

5 Según The Economist (13/06/2009), España e Irlanda experimentan una resaca después de un auge prolongado en el sector de la construcción, que si bien les proveyó un crecimiento económico y de empleos por arriba del promedio en la zona, les dejó altos costos de producción, que les dificultan la recuperación. El caso de España se distingue por la participación de mano de obra migrante (principalmente proveniente de África) durante la época de auge. De acuerdo con 
national/ Ripplewood y el consorcio austrocanadiense Magna en combinación con su socio ruso Sberbank. Finalmente, la operación de compra-venta favoreció a la dupla Magna-Sberbank y se supone que entraría en vigor a partir de noviembre de 2009. La decisión de GM para vender su filial a Magna estuvo influenciada en gran parte por el gobierno alemán, que a través de su generoso préstamo trató de asegurar la mayor parte de los puestos de trabajo de New Opel para los alemanes. Estaban en juego 50 000 empleos, repartidos en plantas ubicadas en España, Polonia, Gran Bretaña, Bélgica y Alemania. Con el triunfo de Magna, se aseguraría la permanencia de las plantas alemanas en Rüsselheim, Bochum, Keiserslautern y Eisenach; por el contrario, las plantas de Antwerpen y Luton, en Bélgica e Inglaterra respectivamente, enfrentarían

el cierre total de sus operaciones. Entre las medidas para sanear la empresa, serían eliminados 11000 empleos, más de 4000 de éstos en plantas alemanas. New Opel se concentraría en el mercado europeo con dos modelos: Insignia y Astra. La armadora rusa GAZ, productora del legendario Volga, desempeñaría un papel preponderante en la venta de autos en ese país. Además de los alemanes, también los polacos se habrían beneficiado por ese contrato. Bajo el nuevo consorcio, su planta de Gliwice podría haber producido 140000 autos. Polonia se perfilaba como un lugar bastante competitivo por sus bajos costos de mano de obra. Sin embargo, las protestas de la Comisión Europea al calificar la operación como una práctica de comercio abiertamente desleal, así como el rediseño de la estrategia de General Motors frente a su filial Opel, echaron abajo el proyecto a principios de noviembre de 2009, un día después de que la canciller alemana había visitado los Estados Unidos, lo cual representó un fracaso del gobierno alemán en su política de empleo y un roce diplomático con Norteamérica al ser ese gobierno socio mayoritario (60\%) de GM. La decisión dio un importante giro en torno a qué país se vería más afectado por la reducción de puestos de trabajo. En virtud de que para sanearse la empresa requería un apoyo de $3.3 \mathrm{mme}$ y una reducción de $30 \%$ en sus costos, los gobiernos involucrados se vieron obligados a ofertar distintos paquetes de apoyo para evitar salir afectados por la eliminación de más de 10000 puestos de trabajo (Wirtschaftswoche, 09/11/2009: 46-52).

\section{Países de la Unión Europea no miembros de la Zona Euro}

En lo referente a los países que no son miembros de la Zona Euro, el análisis resulta interesante toda vez que éstos, salvo la Gran Bretaña, Suecia y Dinamarca, tienen la intención de integrarse a esa zona en un futuro cercano. Ello implica corregir sus agregados macroeconómicos con base en los criterios de convergencia de Maastricht. 
Gráfica 9

Saldo de la cuenta corriente con respecto al PIB en países de la Unión Europea no miembros de la Zona Euro (2008)

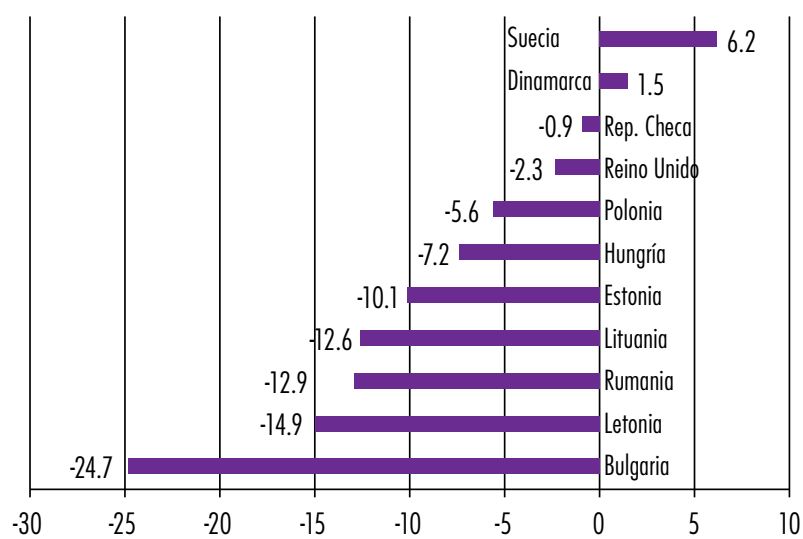

Gráfica 10

Deuda pública con respecto al PIB 2009 en países de la Unión Europea no miembros de la Zona Euro (\%)

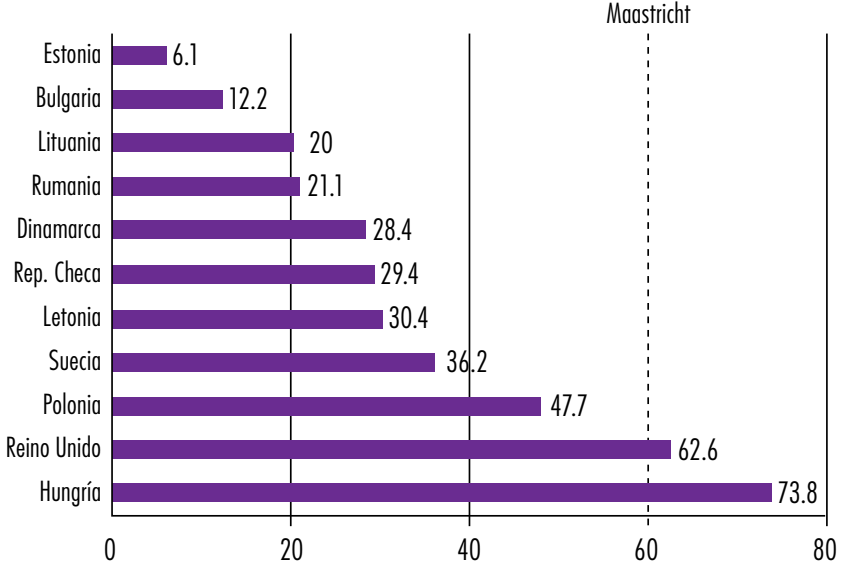

Fuente: European Commission (19 de enero de 2009). Interim Forcast. Directorate- General for Econom and Financial Affairs. Disponible en: http://ec.europa.eu/economy_finance/pdf/2009/interimforecast january/interim_forecast_jan_2009_en.pdf

Las gráficas 9 y 10 enlistan los países con los más altos déficit de cuenta corriente y endeudamiento público con respecto al PIB, resultado a su vez de pronunciados déficit fiscales. El más alto déficit de cuenta corriente lo presenta Bulgaria, con -24\% respecto a su PIB; le siguen, en orden de importancia, Letonia, Rumania, Lituania, Estonia, Hungría y Polonia, con cifras de -14.9\%; -12.9\%, -12.6\%; -10.1\%; -7.2\%, y $-5.6 \%$, respectivamente. En lo referente al endeudamiento público, los países que 
rebasan el criterio de convergencia de Maastricht son Hungría y el Reino Unido, con $73.8 \%$ y $62.6 \%$, respectivamente. El primer indicador es resultado de importantes transferencias de ahorro externo que, de revertirse, podría sumir a esas economías en una espiral inflacionaria a partir de depreciaciones recurrentes (Krugman, 1998).

Gráfica 11

Crecimiento económico 2009 en países no miembro de la Zona Euro

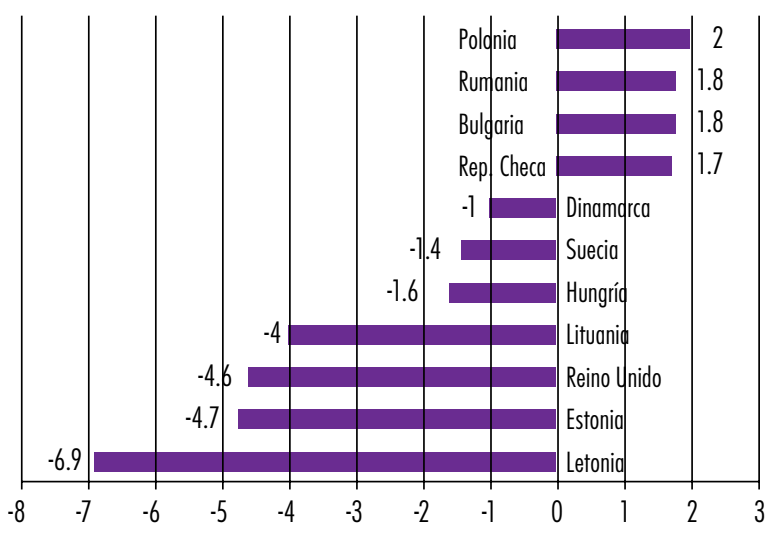

Gráfica 12

Tasa de inflación anualizada 2008 en países no miembro de la Zona Euro (\%)

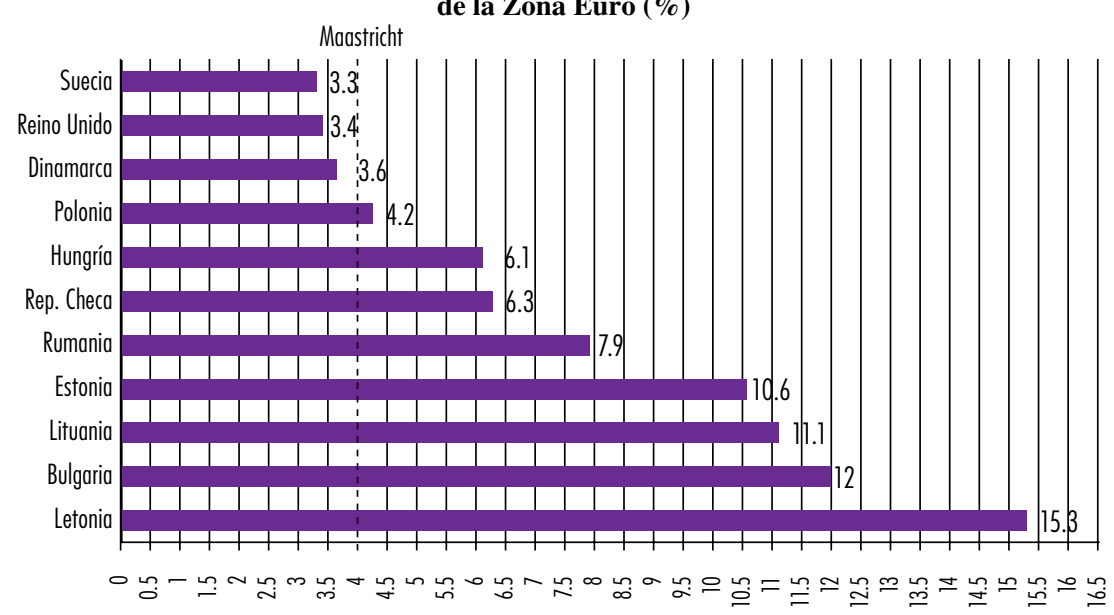

Fuente: European Commission (19 de enero de 2009). Interim Forcast. Directorate- General for Economic and Financial Affairs. Disponible en: http://ec.europa.eu/economy_finance/pdf/2009/interimforecastjanuary/ interim_forecast_jan_2009_en.pdf 
Gráfica 13

Tasa anual de desempleo 2009 en países de la Unión Europea no pertenecientes a la Zona Euro (\%)

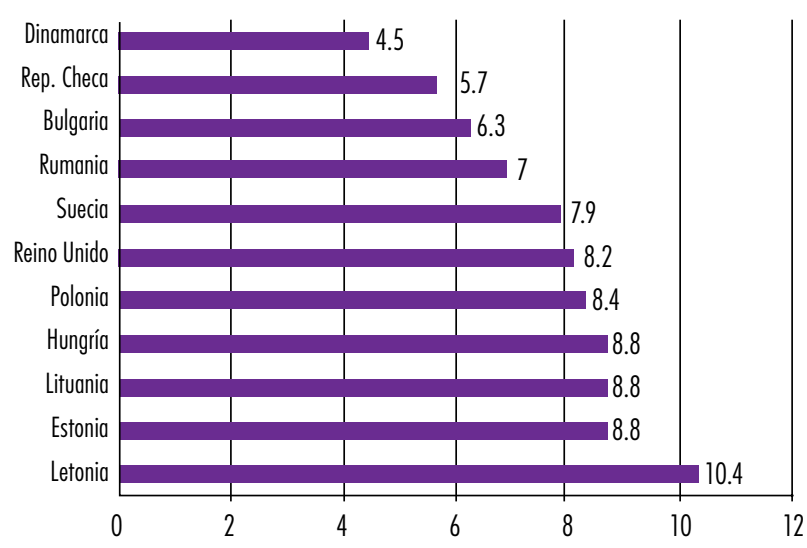

Gráfica 14

Puntaje de solidez económica de países no miembro de la Zona Euro ante la crisis económica de 2009

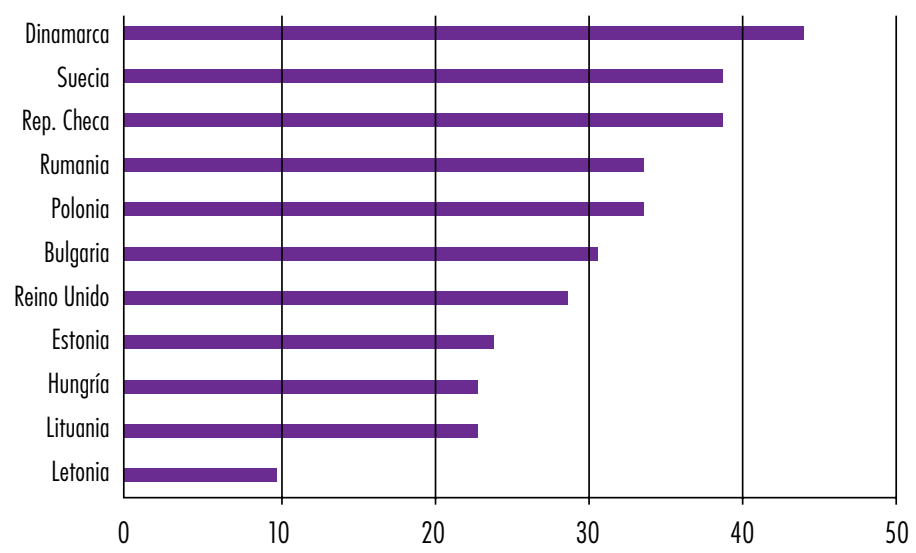

Fuente: European Commission (19 de enero de 2009). Interim Forcast. Directorate-General for Economic and Financial Affairs. Disponible en: http://ec.europa.eu/economy_finance/pdf/2009/interimforecastjanuary/ interim_forecast_jan_2009_en.pdf

Las gráficas 11 y 12 muestran el desempeño de los países no miembro de la Zona Euro en relación con el crecimiento económico y la inflación. El impacto de la crisis en 2009 se reflejó en severas caídas del PIB. En este contexto, Letonia encabeza la lista con un retroceso económico de -6.9\%; le siguen Estonia, el Reino Unido y Lituania, con descensos de $-4.7 \%,-4.6 \%$, y $-4 \%$, respectivamente. Por el contrario, los países que no experimentaron una recesión fueron Polonia, Rumania, 
Bulgaria y la República Checa. Cabe destacar que estos países depreciaron sus respectivas monedas como consecuencia de las fuertes salidas de capital y el colapso de sus mercados bursátiles. Ello se manifestó en un incremento en el nivel de precios. En la gráfica 12 se presentan los niveles inflacionarios de estos países, así como el límite de Maastricht, lo que a su vez indica qué tanto la crisis económica los aleja del nivel requerido para aspirar a formar parte de la Zona Euro. Letonia encabeza la lista de los países con mayor inflación, con $15.3 \%$ anual; le siguen Bulgaria, Lituania, Estonia, Rumania, la República Checa y Hungría, con índices de $12 \%, 11.1 \%, 10.6 \%, 7.9 \%, 6.3 \%$ y $6.1 \%$, respectivamente. En la gráfica 13 se muestran los países con mayor desempleo: nuevamente Letonia aparece en primer lugar, con 10.4\%; Estonia, Lituania, Hungría, Polonia y el Reino Unido presentan tasas que oscilan entre $8 \%$ y $9 \%$. La gráfica 14 representa la suma de los puntos de cada país según el lugar que ocupa en el grupo en relación con los índices macroeconómicos analizados, cuyas cifras se toman de la tabla 3. Cinco fueron los países más afectados: Letonia, Lituania, Hungría, Estonia y el Reino Unido; mientras que los no afectados fueron Dinamarca, Suecia, la República Checa, Rumania y Polonia. En 2008, S\&P asignó a los cinco países más afectados las calificaciones: $\mathrm{BBB}+$; A-; BBB+; A y AAA para el Reino Unido.

El escrito de Knogler (2009) respalda nuestra apreciación, aunque sólo se concentra en los EU-10 o países del Este de Europa ${ }^{6}$. Asegura que estas naciones sufrieron las consecuencias de la recesión de manera pronunciada. Los EU-10 se integraron a la economía de la Unión Europea como proveedores ofreciendo mano de obra calificada a bajo costo. Pero a comienzos de 2008 experimentaron fuertes presiones cambiarias ligadas a la fuga de capitales y la imposibilidad de financiar sus déficit externos. Una caída en sus respectivos mercados accionarios desvalorizó activos y detonó una sequía inmediata en los créditos, tanto al sector productivo como al consumo. El sector industrial de este grupo de países se había colapsado en $20 \%$ a principios de 2009. Los que se vieron más golpeados fueron los que habían ligado su crecimiento económico con su sector exportador ${ }^{7}$; tal es el caso de la República Checa, Hungría, Eslovenia y Eslovaquia. Éstos mantienen a su vez fuertes lazos comerciales especialmente con Alemania, y concentran su comercio en productos de la rama automotriz

6 Éstos son la República Checa, Hungría, Polonia, Eslovaquia, Eslovenia, Estonia, Lituania, Letonia, Bulgaria y Rumania.

7 En términos del PIB, el coeficiente de exportación para 2008 fue: República Checa, 66.9\%; Hungría: 69\%; Polonia: 31.6\%; Eslovaquia: 74.3\%; Eslovenia: 62.5\%; Estonia: 53\%; Letonia: 29.7\% ; Lituania: 49.8\%; Bulgaria: 44.8\%, y Rumania: 24.5\% (Knogler, 2009: 31). 
y electrónica. Sus exportaciones cayeron, pese a haber depreciado sus respectivas monedas en $15 \%$ promedio. Además, también experimentaron un descalabro en su sector inmobiliario y un desamparo en el sector financiero, ya que este último está mayoritariamente en manos de la banca extranjera (Austria, Alemania e Italia).

Tabla 3

\begin{tabular}{|c|l|c|c|c|c|c|}
\hline \multicolumn{7}{|c|}{ Países de la Unión no miembro de la Zona Euro } \\
\hline Clave & País & $\begin{array}{c}\text { Menor crecimiento } \\
\text { económico 2009 }\end{array}$ & $\begin{array}{c}\text { Mayor déficit } \\
\text { cuenta corriente/PIB }\end{array}$ & $\begin{array}{c}\text { Tasa más alta } \\
\text { de desempleo 2009 }\end{array}$ & $\begin{array}{c}\text { Mayor deuda/ } \\
\text { PIB 2009 }\end{array}$ & $\begin{array}{c}\text { Más alta tasa } \\
\text { de inflación 2008 }\end{array}$ \\
\hline LV & Letonia & 1 & 2 & 1 & 5 & 1 \\
\hline LT & Lituania & 4 & 4 & 3 & 9 & 3 \\
\hline HU & Hungría & 5 & 6 & 4 & 1 & 7 \\
\hline EE & Estonia & 2 & 5 & 2 & 11 & 4 \\
\hline UK & Reino Unida & 3 & 8 & 6 & 2 & 10 \\
\hline BG & Bulgaria & 9 & 1 & 9 & 10 & 2 \\
\hline PL & Polonia & 11 & 7 & 5 & 3 & 8 \\
\hline RO & Rumania & 10 & 3 & 8 & 8 & 5 \\
\hline CZ & Rep. Checa & 8 & 9 & 10 & 6 & 6 \\
\hline SE & Suecia & 6 & 11 & 7 & 4 & 11 \\
\hline DK & Dinamarca & 7 & 10 & 11 & 7 & 9 \\
\hline
\end{tabular}

Fuente: European Commission (19 de enero de 2009). Interim Forcast. Directorate- General for Economic and Financial Affairs. Disponible en: http://ec.europa.eu/economy_finance/pdf/2009/interimforecastjanuary/ interim_forecast_jan_2009_en.pdf

Por otro lado, sus respectivos déficit fiscales y de cuenta corriente condujeron a un disparo de los spreads en CDS (Credit Default Swaps), reflejando un mayor riesgo país, en virtud de que muchas de las deudas fueron contraídas en divisas (euros y dólares). La deuda pública en la zona EU-10 ascendió en promedio 73\% a finales de 2008, situación que obligó a varios países a solicitar créditos al FMI. Destaca el caso de Hungría, cuya deuda pública total (pública y privada) se estimó en $121.4 \%$ del PIB. Hungría entró en un problema de pagos al depreciar su moneda y tuvo que solicitar un préstamo de $25 \mathrm{mme}$ al Banco Mundial y el FMI. De manera similar, después de alcanzar tasas de crecimiento económico por arriba del promedio, Lituania entró en recesión desde principios de 2008. El sector inmobiliario había despuntado hasta esa fecha con financiamiento de la banca extranjera. Dos tercios de los créditos fueron hipotecarios y se extendieron en momentos de auge en el ramo. Cuando los precios de los inmuebles se colapsaron, los bancos restringieron los créditos. El gobierno lituano solicitó un préstamo de $7.5 \mathrm{mme}$ a cambio de poner en marcha un programa de ajuste. También Rumania recibió un préstamo por $17.1 \mathrm{mmd}$ para responder a presio- 
nes de balanza de pagos y cuentas públicas. Quienes mejor lograron resistir el embate de la crisis fueron la República Checa y Polonia. Sus agregados macroeconómicos explican este resultado: tanto la deuda pública como el déficit fiscal permanecieron dentro de los límites que marcan los criterios de convergencia de Maastricht y el déficit externo fue poco relevante. En estos dos países los créditos en moneda extranjera fueron mesurados. No obstante, Polonia obtuvo un préstamo por $20 \mathrm{mmd}$ por parte del FMI como respaldo para llevar a cabo reformas estructurales.

Un caso peculiar fue el de la Gran Bretaña: a finales de 2009, su deuda pública se incrementaba en 36000 euros cada cinco segundos, una cantidad superior al ingreso promedio anual de un trabajador en ese país. La agencia calificadora Fitch advirtió que de los países de la Unión con calificaciones AAA, la Gran Bretaña era el primer candidato a un ajuste a la baja, mientras que $S \& P$ bajó su calificación de estable a negativo en mayo de 2009. El déficit público de GB es el más grande después de la Segunda Guerra Mundial y el segundo mayor de los G20 después de los Estados Unidos. A raíz del cuantioso rescate bancario, así como de la reducción de los impuestos, el déficit público se disparó de 5\% en 2008 a 12.2\% del PIB en 2009; se habla de un desembolso de 1 billón de libras esterlinas para estabilizar el sistema financiero; y para 2010 se estima un déficit de $12.9 \%$ del PIB. El desequilibrio fiscal se originó años antes de la crisis y tuvo que ver con el financiamiento del sistema de salud. Se estima una caída de $4.9 \%$ en el PIB para 2009 con un desempleo de 7.8\%, y de $19.2 \%$ en jóvenes, principalmente entre los neets (not in education, employment or training). A pesar de poner en marcha una agresiva política monetaria expansiva, la economía no logró repuntar, pero sí provocó la depreciación de la libra esterlina con respecto a las demás monedas en casi $25 \%$, lo cual constituyó un récord histórico (Wirtschaftswoche, 16/11/2009: 42).

\section{El caso de Grecia}

El gobierno de Grecia comenzó a dar a conocer sus dificultades de pago a finales de 2009, tras recibir el ajuste a la baja en la calificación de su deuda soberana por Fitch, dando así inicio a una controversia que sembró nuevamente desconfianza en la Zona Euro. El euro volvió a caer después de una breve recuperación, de US \$1.45 en enero de 2010 a US $\$ 1.33$ por unidad a mediados de abril de ese mismo año. El caso griego puso el dedo en la llaga al cuestionar la solidez de uno los fundamentos más importantes sobre los que descansa la moneda europea y que comentamos con anterioridad: la cláusula de no rescate (no bail out clause). En este contexto destacan dos aspectos: las características del paquete de rescate y la postura alemana. 
El paquete de rescate. A finales de marzo de 2010, los países miembro de la Zona Euro, junto con el FMI, anunciaron un paquete de rescate que tuvo como único propósito lograr bajar las tasas de interés que el mercado exigía a la compra de títulos de deuda griega. Sin embargo, para mediados de abril de 2010, las tasas continuaban creciendo; Fitch volvió a ajustar la deuda soberana del gobierno griego, asignándole esta vez la nota BBB-. Ello contribuyó a que las tasas se dispararan a niveles de $7.6 \%$ y $7.5 \%$ anuales en instrumentos de dos y 10 años, respectivamente. Y eso no sucedió hasta que Jean-Claude Trichet, director del Banco Central Europeo, declaró a los medios que una bancarrota del gobierno griego estaba totalmente descartada. Tal noticia se interpretó no sólo como un sí al apoyo financiero a Grecia, sino como relajación a la restricción que supone la no bail out clause. Y es que los mercados financieros advirtieron una falta de claridad en el rescate anunciado en marzo, pues se suponía que era sólo una salida de emergencia, y que el gobierno griego tenía que seguir buscando recursos en el mercado de capitales a tasas abiertas, lo cual lo acercaba más al default. Eso hizo que los inversionistas se deshicieran de los títulos griegos y exigieran tasas de interés aún mayores por el riesgo implícito creciente. Por su parte, el gobierno griego se comprometió a reducir su déficit a 4\% del PIB, mediante severos recortes al gasto público, así como a acelerar el proceso de privatización de empresas paraestatales. Al inicio se hablaba de un monto de $30 \mathrm{mme}$, de los cuales el FMI aportaría entre 10 y 12 mme, Alemania 8 mme y el resto vendría de los países miembro. Después se dijo que esa cantidad era insuficiente, pues tan sólo para finales de mayo de 2010, Grecia tenía compromisos de pago por $13 \mathrm{mme}^{8}$. Según expertos, las necesidades de financiamiento hasta 2012 podrían oscilar entre 90 y $120 \mathrm{mme}$; mientras que el ministro de Finanzas de la Unión Europea hablaba de un programa de ayuda por tres años.

La postura de Alemania. Sin duda Alemania no sólo es la economía más grande de la Unión Europea, sino una de las más ricas y saludables en términos macroeconómicos. A pesar de haber declarado en diferentes foros que Alemania no apoyaría

8 "Nadie trata de sujetar un cuchillo al caer", es una de las frases que los mercados financieros vertieron en torno a títulos de deuda griegos. Según el periódico alemán Handelsblatt (14/04/2010: 36), el gobierno griego logró, después de la declaración de Jean Claude Trichet, colocar deuda por $1.56 \mathrm{mme}$ en el mercado de capitales a tasas de interés de $4.5 \%$ y $4.8 \%$ a medio año y un año. Además, las autoridades se han propuesto obtener 2.5 mme por concepto de privatizaciones. Entre los prospectos a privatizar están aeropuertos, refinerías, compañías de telecomunicación, lotería, etc. Uno de los beneficiados en este proceso podría ser las empresas alemanas. 
a Grecia ${ }^{9}$, la canciller alemana Angela Merkel finalmente cedió a las presiones en pro de la estabilidad del euro, aportando el mayor monto en el paquete de rescate financiero. Ello hizo que la jefa de Estado enfrentara severas críticas al interior de su país, pues se manejaba la tesis de que con ello se fomentaría el moral hazard ${ }^{10} \mathrm{y}$, una vez otorgado el apoyo a Grecia, otras naciones en dificultades fiscales (e.g. los PIIGS) esperarían el mismo trato por parte de los alemanes. Sin embargo, quienes estaban a favor del rescate, argumentaban que éste representaba una inversión para Alemania, pues vender títulos de deuda alemana a una tasa de 3\% y comprar títulos de deuda griegos que pagan arriba de $5 \%$ suponía un remanente positivo. No obstante, a largo plazo ello podría representar el inicio del fin de la estabilidad del euro.

\section{Conclusiones}

La crisis financiera, inmobiliaria y fiscal de los Estados Unidos de Norteamérica afectó sustancialmente a la Unión Europea. Ello se evidenció a partir de una depreciación del euro respecto al dólar a finales de 2008 y principios de 2009. A partir de la flexibilización de los criterios de Maastricht, así como del impacto del gasto ejercido por programas de apoyo gubernamentales, el euro y la economía europea volvieron a fortalecerse, pero sólo durante 2009. La crisis fiscal de Grecia provocó nuevamente la caída del euro y de los mercados bursátiles europeos en el primer trimestre de 2010.

Desde su creación, la Zona Euro ha mantenido una inflación promedio que apenas ha rebasado el $2 \%$, y lejos de los pronósticos acerca de su fracaso, ha probado ser una divisa sumamente estable. En este contexto, se señala una responsabilidad del Banco Central Europeo en la crisis de 2009, por ejercer una política monetaria de corte one size fits all; es decir, una misma tasa para la zona que resultaba alta para países con baja inflación como Alemania y muy baja para otros con fuertes presiones inflacionarias, como tradicionalmente ha sido el caso de los PIIGS. De ello se infiere también que la disminución de la tasa de interés paulatina de 2000 a 2005 financió el auge en el sector de la construcción de aquellos países que durante la crisis experimentaron un colapso en su sector inmobiliario: España, Grecia e Irlanda.

$9 \quad$ El mismo ministro de Finanzas alemán, Wolfgang Schäuble, fue uno de los fuertes opositores al paquete de rescate, e incluso declaró que prefería la salida de Grecia de la Zona Euro. Asimismo, manifestó que un Fondo Monetario Europeo para rescatar a gobiernos en dificultades de pago sería igualmente contradictorio con el pacto de estabilidad de Maastricht.

10 Término usado en finanzas, se traduce como "privatizar las ganancias y socializar las pérdidas". En este caso, se habla de un rechazo a pagar la irresponsabilidad fiscal de un gobierno extranjero. 
La sostenibilidad de la divisa europea dependerá de la voluntad política de los países que más aportan al PIB de la Zona Euro. Este grupo lo encabeza Alemania, seguido por Francia, Italia, Holanda y España; juntos aportan más de 30\% del PIB. El paquete de rescate griego ha tensionado dos fuerzas que tiran en sentido opuesto: la estabilidad monetaria basada en la cláusula de no rescate, ligada estrechamente a la independencia del Banco Central Europeo; y los peligros inflacionarios que se derivan de apoyar a gobiernos con desequilibrios fiscales excesivos. Todo parece indicar que el caso griego es sólo la punta del iceberg de un grave problema fiscal generalizado en muchas de las economías pertenecientes a la OCDE. Hay tres factores que hacen pensar que muy pronto, cada vez más gobiernos se declararán en bancarrota: $a$ ) un muy bajo crecimiento económico con pocas posibilidades de recaudar; $b$ ) alza de las tasas de interés reales, lo que también oprimirá la demanda real y elevará los costos de la deuda, y c) el envejecimiento de la población en las economías industrializadas, que disparará los gastos en salud y pensiones.

Para el grupo de países miembro de la Unión Europea que aún se encuentra fuera de la Zona Euro, la crisis de 2009 representó un tropiezo en su intento por alcanzar los criterios de Maastricht, en especial para los países bálticos. Por el contrario, para aquellos que pudieron sortear la crisis con mayor éxito, su entrada al euro se torna más optimista, aunque aún no hayan medido las consecuencias. Tal es el caso de Polonia, por ejemplo, que logró evadir las secuelas de la crisis por su bajo grado de apertura comercial, factor que podría cambiar una vez fuera de la Zona Euro. Por su parte, el deterioro de la economía británica quizá contribuya a realizar severos ajustes a su desequilibrio fiscal y problema de deuda. Finalmente, México puede aprender tres lecciones de la experiencia europea: $a$ ) la crisis mundial de 20082009 se traducirá en problemas fiscales e inflacionarios generalizados; $b$ ) el riesgo de mantener reservas en dólares y en euros se elevará conforme se intensifiquen los desequilibrios fiscales, y c) los estados que se declaren en bancarrota, perderán soberanía de manera sustancial. 


\section{Bibliografía}

Greenspan, Alan, The Age of Turbulence, Penguin Books, 2008.

De Grawe, Paul, The Economic of Monetary Integration, Oxford University Press, 1997.

Dettmer, Markus, Frank Dohmen, Dietmar Hawranek y Janko Tietz, "Arbeitsmakrt. Das Kleine Wunder", Der Spiegel, núm. 49, 2009, pp. 78-81.

Eichengreen, Barry, Toward a New International Financial Architecture, Washington DC, Institute for International Economics, 1999.

European Commission, Interim Forcast. Directorate-General for Economic and Financial Affairs, 19 de enero de 2009, en: http:// ec.europa.eu/economy_finance/pdf/2009/ interimforecastjanuary/interim_forecast_ jan_2009_en.pdf

Focus, "Finanzkrise. Lehmans rote liste", Focus, núm. 38, 2009, pp. 128-130.

Frank, S., M. Kietzmann, B. Reitschuster, F. Schwab, M. Wisniewski y G. Schattauer, "Im PS-Poker steigt die Spannung. General Motors bleibt eine ungeliebte Mutteraber die Tochter Opel wird wertvollste Marke des wieder erstarkten Automobilriesen”, Focus, núm, 46, 2009, pp. 30-35, en http://www.focus.de/finanzen/news/opel/ opel-im-ps-poker-steigt-die-spannung aid_452044.html

Fritzler, M. y G. Unser, Die Europäische Union, München, Bundeszentrale für politische Bildung, 1998.

Handelsblatt, Grechische Tragödie in drei Akten: 1, 14 de abril de 2010 . , Griechen erreichen Achtungserfolg: 36, 14 de abril de 2010.

Hoffritz Jutta, Maximale Schaden, Die Zeit: 25, 22 de octubre de 2009.

Kindleberger, Charles, The World in Depression 1929-1939, Londres, University of California Press, 1986.

Vol. 41, núm. 161, abril-junio / 2010
Knogler, Michael, "Die osteuropäischen EUMitglieder im Griff der Wirtschafts-und Finanzkrise", Orientierung zur Wirtschaftsund Gesellschaftspolitik, núm. 120, 2 , 2009, pp. 27-35.

Körner, A., K. Behrend, B. Johan, M. Kietzmann y N. Mattes, "Klamm trotz Aufschwung", Focus, núm. 49, 2009, pp. 134-137.

Krugman, Paul, Currencies and Crisis, Londres, MIT Press, 1998

Meyer, Dirk, "Finanzmarktkrise: Stabilität der Euro-Zone in Gefahr?", Orientierungen zur Wirtschafts-und Gesellschaftspolitik, núm. 119, enero de 2009, pp. 49-53.

McKinnon, R.I., "Optimum Currency Areas", The American Economic Review, vol. LIII, núm. 4, septiembre de 1963.

Mundell, R.A., "A Theory of Optimum Currency Areas", The American Economic Review, vol. LI, núm. 4, septiembre de 1961.

The Economist, "Holding together. A special report on the euro area", The Economist, 13 de junio de 2009, pp. 3-16.

,"The party's over. A special report on Spain", The Economist, 8 de noviembre de 2008, pp. 1-20.

The Wall Street Journal, "Ratings firm shifts outlook for Spain", The Wall Street Journal, 10 de diciembre de 2009, p. 4.

Voswinkel, Johannes, "Russlands Rüsselsheim", Die Zeit, núm. 30, julio de 2009, p. 25.

Wirtschaftswoche, Kapital Mangel, núm. 49, 30 de noviembre de 2009, pp. 21-24.

, Beschämt y getröstet, núm. 49, 30 de noviembre de 2009, pp. 30-33.

Harte Weg, núm. 47, 16 de noviembre de 2009, p. 42.

, Hang zu Provokation, núm. 47, 16 de noviembre de 2009, p. 43.

, Objekt der Begierde, núm. 46, 9 de noviembre de 2009, pp. 46-50.

, Verlorene Generation, núm. 33, 10 de agosto de 2009, p. 23.

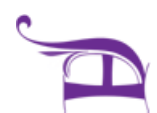

